\title{
Prognostic markers of heart failure in patients undergoing peritoneal dialysis
}

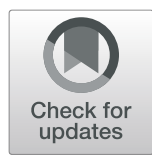

Kohsuke Terada, Yukinao Sakai, Yuichiro Sumi, Koji Mugishima, Sayuri Kawasaki, Fumiaki Itagaki,

Takehisa Yamada and Shuichi Tsuruoka

\begin{abstract}
Background: Heart failure is a significant cause of death and hospitalization in dialysis patients. Controlling the volume status in PD, especially, is difficult, and transferring the PD patients to hemodialysis results mainly from ultrafiltration failure. Thus, the control of heart failure and markers as its predictors in PD patients are of the utmost importance. In this study, we aim to confirm the utility of BNP and NT-proBNP as predictive markers of heart failure and to identify new markers in PD patients.
\end{abstract}

Methods: Our study involved 29 patients who had been undergoing PD. The following were determined: body mass index, primary disease, PD vintage, D/P ratio, D/D ratio, left ventricle ejection fraction, left atrial dimension, left ventricular mass index, cardiac index, change in body weight, CTR, BNP, NT-proBNP, BUN, creatinine, TP, Alb, Na, K, $\mathrm{Cl}, \mathrm{Ca}, \mathrm{P}, \mathrm{iPTH}, \mathrm{Hb}, \mathrm{Ht}, \mathrm{s} \beta 2 \mathrm{MG}, \mathrm{T}-\mathrm{SAT}$, and weekly $\mathrm{Kt} / \mathrm{N}$ urea and $\mathrm{CCr}$. Furthermore, we categorized the patients' disease using the NYHA classification and evaluated these indicators.

Results: The BNP concentration was positively correlated with that of NT-proBNP. In addition, the CTR was positively correlated with BNP and NT-proBNP concentrations. By one-way analysis of variance, the NYHA classification was statistically associated with BNP, NT-proBNP, CTR, Alb, Hb, Ht, sß2MG, ferritin, and weekly Kt/N urea and $\mathrm{CCr}$, of which $\mathrm{Hb}$ and $\mathrm{Ht}$ were the most significant. According to the logistic regression analysis of the heart failure risk using the NYHA classification, the $\mathrm{CTR}, \mathrm{Hb}, \mathrm{Ht}$, and weekly $\mathrm{CCr}$ were statistically significant in the univariate analysis. However, none remained statistically significant, and among them, weekly CCr has the highest specificity in the multivariate analysis. Furthermore, the following measurements were associated with a high risk of heart failure: $\mathrm{CTR}>51.9 \%, \mathrm{Hb}<9.4 \mathrm{~g} / \mathrm{dL}, \mathrm{Ht}<29.2 \%$, and weekly $\mathrm{CCr}<80.9 \mathrm{~L} /$ week $/ 1.73 \mathrm{~m}^{2}$.

Conclusion: Compared with the classical examinations, BNP and NT-proBNP are less useful as markers of heart failure in PD patients. Consequently, anemia and weekly CCr are the risks of heart failure.

Trial registration: This study was retrospectively registered to the University Hospital Medical Information Network (UMIN no. 000041762).

Keywords: Peritoneal dialysis, Heart failure, Prognostic marker, Natriuretic peptide, Anemia

\section{Background}

Heart failure is a significant cause of death in patients undergoing dialysis in Japan [1], and the highest cause-specific mortality in such patients in the USA is due to cardiovascular diseases, including arrhythmia, cardiac arrest, congestive heart failure (CHF), acute myocardial infarction, and atherosclerotic heart disease [2]. In 2015, the adjusted rate of admission of hemodialysis (HD) and peritoneal

\footnotetext{
* Correspondence: y-sakai@nms.ac.jp

Department of Nephrology, Graduate School of Medicine, Nippon Medical School, 1-1-5 Sendagi, Bunkyo-ku, Tokyo 113-8603, Japan
}

dialysis (PD) patients in the USA was 1.7 per patient-year, and cardiovascular disease was the second most common cause of hospitalization following infection [2]. Therefore, the control of heart failure in such patients is of the utmost importance.

In chronic PD patients, volume control is a significant predictor of outcome [3], and ultrafiltration failure is a significant cause of the technique failure of PD, subsequently resulting in the transfer of patients to HD [4]. A study in Japan reported that ultrafiltration loss is the most prominent cause of withdrawal from continuous ambulatory PD

(c) The Author(s). 2019 Open Access This article is distributed under the terms of the Creative Commons Attribution 4.0 International License (http://creativecommons.org/licenses/by/4.0/), which permits unrestricted use, distribution, and reproduction in any medium, provided you give appropriate credit to the original author(s) and the source, provide a link to the Creative Commons license, and indicate if changes were made. The Creative Commons Public Domain Dedication waiver (http://creativecommons.org/publicdomain/zero/1.0/) applies to the data made available in this article, unless otherwise stated. 
(CAPD) in patients undergoing PD for $>6$ years [5], implying that strategies to prevent and manage ultrafiltration failure may help in maintaining the patient to remain on PD [6]. Also, heart failure is a highly prevalent complication in patients on long-term PD. Moreover, patients with a history of heart failure have a significantly lower overall cumulative probability of survival than those without [7]. Therefore, the prediction and prevention of the first heart failure and its recurrence are crucial.

To improve the quality of treatment in PD patients, markers as predictors of heart failure in PD patients are necessary. Currently, in addition to the change in body weight $(\Delta \mathrm{Wt})$ and cardiothoracic ratio $(\mathrm{CTR})$, the brain natriuretic peptide (BNP) and N-terminal pro-brain natriuretic peptide (NT-proBNP) levels are used as markers of heart failure. However, their effectiveness in predicting the disease has not been fully established. To ensure the early diagnosis and intervention of heart failure, the confirmation of the utility of the markers and new predictive markers of heart failure is necessary.

Therefore, in this study, we aim to confirm the utility of BNP and NT-proBNP as predictive markers of heart failure and to identify new markers in PD patients.

\section{Methods}

A total of 29 patients who had been undergoing PD and were regularly followed up at Nippon Medical School Hospital between November 2016 and November 2018 were enrolled. For 3 consecutive months, the following were measured in these patients: $\Delta \mathrm{Wt}(\mathrm{kg}), \mathrm{CTR}(\%)$, BNP (pg/mL), NT-proBNP (pg/mL), BUN (mg/dL), Cr $(\mathrm{mg} / \mathrm{dL}), \mathrm{TP}(\mathrm{g} / \mathrm{dL}), \mathrm{Alb}(\mathrm{g} / \mathrm{dL}), \mathrm{Na}(\mathrm{mEq} / \mathrm{L}), \mathrm{K}(\mathrm{mEq} / \mathrm{L})$, $\mathrm{Cl}(\mathrm{mEq} / \mathrm{L}), \mathrm{Ca}(\mathrm{mg} / \mathrm{dL}), \mathrm{P}(\mathrm{mg} / \mathrm{dL})$, intact parathyroid hormone $(\mathrm{pg} / \mathrm{mL})$, hemoglobin $(\mathrm{Hb})(\mathrm{g} / \mathrm{dL})$, hematocrit $(\mathrm{Ht})(\%)$, serum $\beta 2$ microglobulin (s $\beta 2 \mathrm{MG})(\mu \mathrm{g} / \mathrm{mL})$, ferritin $(\mathrm{ng} / \mathrm{mL})$, transferrin saturation (T-SAT) $(\%)$, urine volume (UV) (mL/day), and weekly $\mathrm{Kt} / \mathrm{V}$ urea and creatinine clearance $(\mathrm{CCr})\left(\mathrm{L} /\right.$ week $\left./ 1.73 \mathrm{~m}^{2}\right)$. In addition, we categorized their disease using the New York Heart Association (NYHA) classification and evaluated the body mass index (BMI) $\left(\mathrm{kg} / \mathrm{m}^{2}\right)$, primary disease, PD vintage, $\mathrm{D} / \mathrm{P}$ ratio, $\mathrm{D} / \mathrm{D}$ ratio, left atrial dimension (LAD) $(\mathrm{mm})$, left ventricular mass index $(\mathrm{LVMI})\left(\mathrm{g} / \mathrm{m}^{2}\right)$, left ventricle ejection fraction (EF) (\%), and cardiac index (CI) as potential background factors. In this study, we defined $\Delta \mathrm{Wt}$ as the change of body weight in these patients between their regular follow-ups every month, and it was based on the patient's self-reporting.

All laboratory values were presented as means \pm standard deviations. The continuous variables were compared using the one-way analysis of variance (ANOVA). $p$ values $<0.05$ were considered statistically significant. All statistical analyses were performed using Prism $^{\circ}$ software version 8 (GraphPad Software, La Jolla, CA, USA). Furthermore, the multiple linear and logistic regression analyses were performed using $\mathrm{JMP}^{\circledR}$ software version 12 (SAS Institute, Cary, NC, USA).

\section{Results}

This study included 21 men and 8 women, with the mean age of $64.14 \pm 14.42$ years. The most frequent primary diseases were diabetes mellitus (11 patients, 37.9\%) and nephrosclerosis (9 patients, 31.0\%). The mean duration of $\mathrm{PD}$ and $\mathrm{D} / \mathrm{P}$ and $\mathrm{s}$ ratios were $12.0 \pm 7.6$ months, and $0.727 \pm 0.203$ and $0.377 \pm 0.132$, respectively. Moreover, the oral medications being administered were angiotensin II receptor blockers (22 patients, $75.9 \%$ ), statins (13 patients, $44.8 \%$ ), diuretics (25 patients, $86.2 \%$ ), and iron supplements (6 patients, 20.7\%). Also, the mean values obtained during cardiac ultrasonography were as follows: LAD, $37.8 \pm 6.0 \mathrm{~mm}$; LVMI, $126.7 \pm 34.1 \mathrm{~g} / \mathrm{m}^{2}$; EF, $67.0 \pm$ 9.9\%; E/e', $15.0 \pm 8.1$; and CI, $3.332 \pm 0.7997$ (Table 1).

The BNP concentration was positively correlated with that of NT-proBNP $(r, 0.794 ; p<0.0001)$ (Fig. 1). Also, the CTR was positively correlated with $\mathrm{BNP}(r, 0.538$; $p<0.0001)$ and NT-proBNP $(r, 0.508 ; p<0.0001)$ concentrations, with similar correlation coefficients. However, $\Delta \mathrm{Wt}$ was not correlated with these parameters

\section{Table 1 Baseline clinical characteristics of the patients}

\begin{tabular}{|c|c|}
\hline Total, $n$ & 29 \\
\hline Female, $n(\%)$ & $8(27.6)$ \\
\hline Age (years) & $64.14 \pm 14.42$ \\
\hline BMI $\left(\mathrm{kg} / \mathrm{m}^{2}\right)$ & $23.60 \pm 3.057$ \\
\hline $\mathrm{DM}, n(\%)$ & $11(37.9)$ \\
\hline Nephrosclerosis, $n$ (\%) & $9(31.0)$ \\
\hline PD duration (months) & $12.04 \pm 7.589$ \\
\hline $\mathrm{D} / \mathrm{P}$ ratio & $0.7273 \pm 0.2034$ \\
\hline D/D ratio & $0.3769 \pm 0.1324$ \\
\hline Weekly Kt/N urea & $1.813 \pm 0.4844$ \\
\hline Weekly CCr (L/week/1.73m²) & $86.31 \pm 36.00$ \\
\hline Urine volume (mL/day) & $919.8 \pm 383.3$ \\
\hline ARB, $n(\%)$ & $22(75.9)$ \\
\hline Statin, $n(\%)$ & $13(44.8)$ \\
\hline Diuretic (\%) & $25(86.2)$ \\
\hline Iron supplementation, n (\%) & $6(20.7)$ \\
\hline LAD (mm) & $37.83 \pm 6.042$ \\
\hline LVMI $\left(g / m^{2}\right)$ & $126.7 \pm 34.14$ \\
\hline $\mathrm{EF}(\%)$ & $66.99 \pm 9.917$ \\
\hline E/e' & $14.98 \pm 8.113$ \\
\hline $\mathrm{Cl}$ & $3.332 \pm 0.7997$ \\
\hline
\end{tabular}

$B M I$ body mass index, $D M$ diabetes mellitus, $P D$ peritoneal dialysis, $A R B$ angiotensin II receptor blocker, $L A D$ left atrial dimension, $L V M I$ left ventricular mass index, $E F$ ejection fraction, $\mathrm{Cl}$ cardiac index 


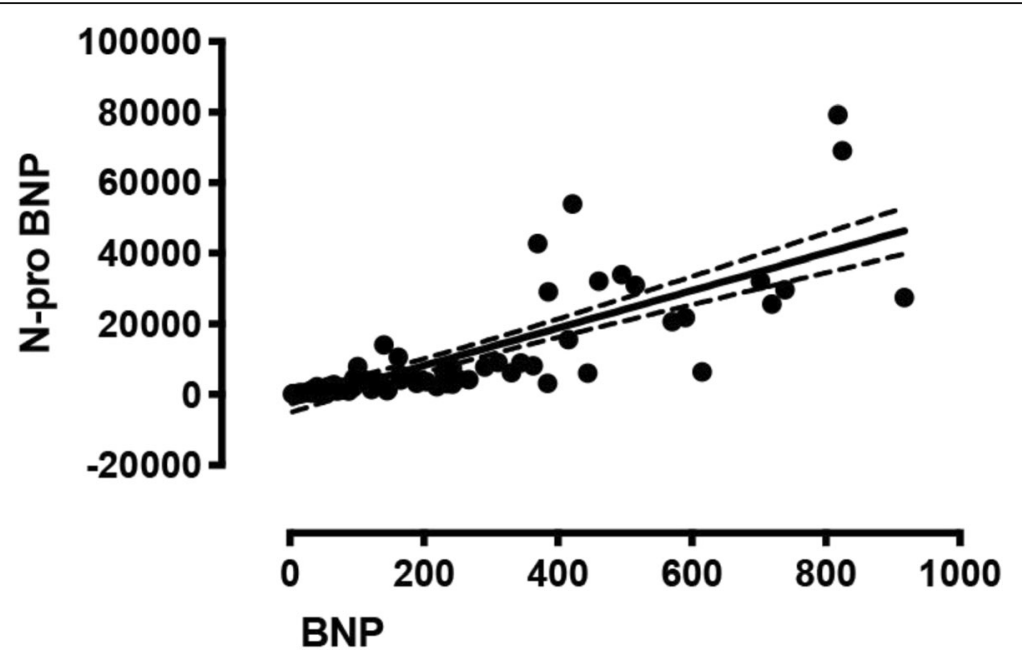

Fig. 1 Correlation between the brain natriuretic peptide (BNP) and N-terminal pro-brain natriuretic peptide (NT-proBNP) concentrations

(BNP and $\Delta$ Wt: $r,-0.0240$, and $p, 0.828$; NT-proBNP and $\Delta \mathrm{Wt}: r,-0.0701$, and $p, 0.524$ ) (Fig. 2).

The NYHA classification was significantly associated with BNP $(p=0.0005)$, NT-proBNP $(p=0.0001)$, CTR $(p<$ $0.0001)$, Alb $(p<0.0001), \mathrm{Hb}(p<0.0001)$, Ht $(p<0.0001)$, sß2MG $(p=0.0497)$, ferritin $(p=0.019)$, and weekly Kt/V urea $(p=0.0456)$ and $\mathrm{CCr}(p=0.0022)$ in the ANOVA (Table 2), of which the relationships with $\mathrm{CTR}, \mathrm{Hb}$, and $\mathrm{Ht}$ showed the highest levels of statistical significance. Although the relationships with BNP and NT-proBNP were significant, their values in patients with NYHA category II were very high. The relationships with weekly $\mathrm{Kt} / \mathrm{V}$ urea and weekly $\mathrm{CCr}$ were also significant, but not UV. Furthermore, although the relationship with ferritin was significant, that with T-SAT was not.

The univariate and multivariable logistic regression models were constructed for the risk of heart failure using the NYHA classification. In the univariate analysis, the CTR (odds ratio [95\% CI], 1.32 [1.12-1.63]; $p=$ 0.0005), Hb (0.165 [0.0393-0.433]; $p<0.0001)$, Ht $(0.583$ $[0.387-0.785] ; \quad p<0.0001)$, and weekly $\mathrm{CCr}(0.944$ [0.880-0.991]; $p<0.0123)$ were statistically significant.

\section{A}
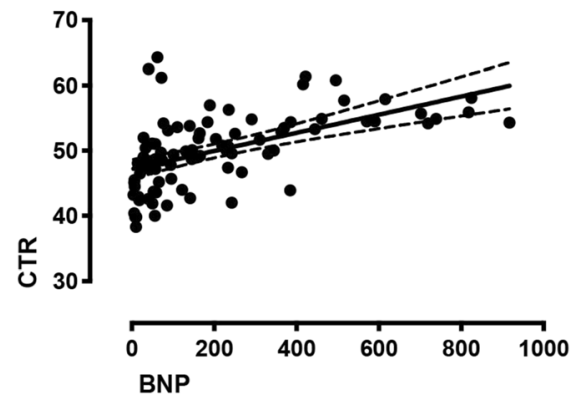

C

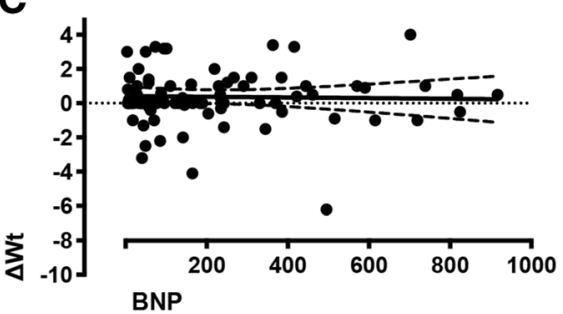

B

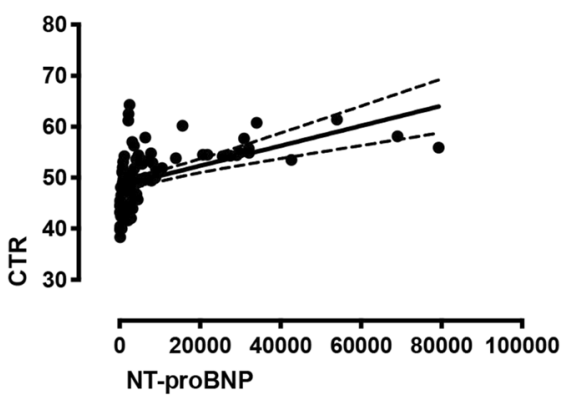

D

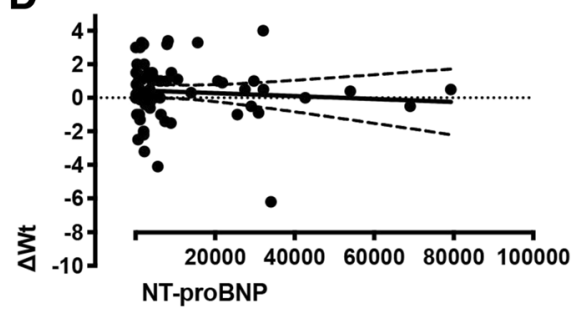

Fig. 2 Correlation between the brain natriuretic peptide (BNP) concentration and cardiothoracic ratio (CTR) (a). Correlation between the Nterminal pro-brain natriuretic peptide (NT-proBNP) concentration and CTR (b). Correlation between the BNP concentration and change in body weight $(\Delta \mathrm{Wt})(\mathbf{c})$. Correlation between the NT-proBNP concentration and $\Delta \mathrm{Wt}(\mathbf{d})$ 
Table 2 Relationships with the New York Heart Association (NYHA) classification, according to ANOVA

\begin{tabular}{|c|c|c|c|c|c|c|}
\hline \multirow[t]{2}{*}{ NYHA } & \multirow[t]{2}{*}{ I $(n=51)$} & \multirow[t]{2}{*}{$\|(n=27)$} & \multirow[t]{2}{*}{ III $(n=4)$} & \multirow[t]{2}{*}{$\operatorname{IV}(n=3)$} & \multicolumn{2}{|l|}{$p$ value } \\
\hline & & & & & One-way ANOVA & For trend \\
\hline BNP (pg/mL) & $133.4 \pm 170.7$ & $341.9 \pm 257.6$ & $232.6 \pm 154$ & $335.1 \pm 250.4$ & 0.0005 & 0.001 \\
\hline NT-proBNP (pg/mL) & $3369 \pm 6639$ & $18,807 \pm 21,661$ & $9107 \pm 5486$ & $10,343 \pm 9462$ & 0.0001 & 0.0026 \\
\hline CTR (\%) & $47.62 \pm 5.179$ & $53.02 \pm 4.157$ & $57.8 \pm 5.532$ & $56.2 \pm 4.403$ & $<0.0001$ & $<0.0001$ \\
\hline$\Delta \mathrm{Wt}(\mathrm{kg})$ & $0.5882 \pm 1.847$ & $-0.2741 \pm 1.859$ & $1.25 \pm 1.529$ & $1.5 \pm 1.706$ & 0.1161 & 0.9675 \\
\hline BUN (mg/dL) & $61.31 \pm 13.89$ & $66.37 \pm 13.84$ & $64.2 \pm 9.248$ & $63 \pm 10.78$ & 0.4886 & 0.3112 \\
\hline $\mathrm{Cr}(\mathrm{mg} / \mathrm{dL})$ & $8.942 \pm 2.972$ & $10.02 \pm 4.38$ & $12.08 \pm 1.015$ & $10.79 \pm 2.915$ & 0.2115 & 0.0536 \\
\hline $\mathrm{TP}(\mathrm{g} / \mathrm{dL})$ & $6.257 \pm 0.6543$ & $6.052 \pm 0.6773$ & $6.05 \pm 0.4041$ & $5.6 \pm 0.2646$ & 0.2436 & 0.0517 \\
\hline Alb (g/dL) & $3.469 \pm 0.5148$ & $2.774 \pm 0.5822$ & $3.375 \pm 0.8139$ & $2.967 \pm 0.5686$ & $<0.0001$ & 0.0007 \\
\hline $\mathrm{Na}(\mathrm{mEq} / \mathrm{L})$ & $139.5 \pm 3.081$ & $137.3 \pm 4.01$ & $140.8 \pm 1.708$ & $140.3 \pm 1.528$ & 0.0342 & 0.5642 \\
\hline $\mathrm{K}(\mathrm{mEq} / \mathrm{L})$ & $4.386 \pm 0.6229$ & $4.578 \pm 0.6635$ & $4.275 \pm 0.6131$ & $4.4567 \pm 0.3512$ & 0.5671 & 0.4656 \\
\hline $\mathrm{Cl}(\mathrm{mEq} / \mathrm{L})$ & $102.2 \pm 4.03$ & $98.78 \pm 3.62$ & $100.8 \pm 2.986$ & $104.3 \pm 2.082$ & 0.0019 & 0.1616 \\
\hline $\mathrm{Ca}(\mathrm{mg} / \mathrm{dL})$ & $8.692 \pm 0.7418$ & $7.8 \pm 0.5038$ & $8.6 \pm 0.8832$ & $8.567 \pm 0.6028$ & $<0.0001$ & 0.0061 \\
\hline$P(\mathrm{mg} / \mathrm{dL})$ & $5.349 \pm 1.433$ & $5.774 \pm 1.711$ & $5.75 \pm 1.406$ & $5 \pm 2.095$ & 0.6276 & 0.6183 \\
\hline iPTH (pg/mL) & $324.3 \pm 220.6$ & $257.3 \pm 157.3$ & $349 \pm 476.4$ & $158.5 \pm 136.7$ & 0.3718 & 0.1913 \\
\hline $\mathrm{Hb}(\mathrm{g} / \mathrm{dL})$ & $10.75 \pm 1.132$ & $9.519 \pm 1.062$ & $8.45 \pm 1.109$ & $8.167 \pm 0.8505$ & $<0.0001$ & $<0.0001$ \\
\hline $\mathrm{Ht}(\%)$ & $32.66 \pm 3.755$ & $29.15 \pm 3.229$ & $25.85 \pm 3.423$ & $25.43 \pm 2.101$ & $<0.0001$ & $<0.0001$ \\
\hline$\beta 2 \mathrm{MG}(\mu \mathrm{g} / \mathrm{mL})$ & $21.91 \pm 8.843$ & $28.08 \pm 13.72$ & $32.97 \pm 18.6$ & $30.97 \pm 14.76$ & 0.0497 & 0.0092 \\
\hline Ferritin (ng/mL) & $177.3 \pm 114.3$ & $331.8 \pm 631.3$ & $736.6 \pm 982.4$ & $698.3 \pm 751.4$ & 0.019 & 0.0027 \\
\hline T-SAT (\%) & $36.64 \pm 12.65$ & $35.63 \pm 16.72$ & $40.76 \pm 17.62$ & $29.96 \pm 13.73$ & 0.7858 & 0.6977 \\
\hline UV (mL/day) & $953.9 \pm 407.2$ & $836.1 \pm 271$ & $962.5 \pm 566.2$ & $1083 \pm 629.2$ & 0.5206 & 0.8444 \\
\hline Weekly Kt/N urea & $1.936 \pm 0.5079$ & $1.62 \pm 0.3536$ & $1.76 \pm 0.6346$ & $1.737 \pm 0.2078$ & 0.0456 & 0.0403 \\
\hline Weekly CCr (L/week/1.73m²) & $97.9 \pm 40.21$ & $70.59 \pm 16.59$ & $60.26 \pm 10.93$ & $66.56 \pm 13.56$ & 0.0022 & 0.0006 \\
\hline
\end{tabular}

However, none remained significant in the multivariate analysis. Additionally, neither ferritin nor T-SAT was statistically significant in the univariate analysis, as well as UV and weekly Kt/V (Table 3).

The Youden indexes (cutoff values), established using the receiver operating characteristic (ROC) curve for the NYHA classification, for CTR (a), Hb (b), Ht (c), and weekly CCr (d) were $>51.9 \%,<9.4 \mathrm{~g} / \mathrm{dL},<29.2 \%$, and $<$ $80.9 \mathrm{~L} /$ week $/ 1.73 \mathrm{~m}^{2}$, respectively, indicating a high risk of heart failure (Fig. 3).

\section{Discussion}

In Japan, heart failure is the leading cause of mortality in dialysis patients [1], and in the USA, cardiovascular diseases most commonly result in death in dialysis patients [2]. Furthermore, in China, cardiovascular complications have been reported to be the second most common cause of death in these patients, following infection [8], and deaths in elderly patients undergoing PD were also shown to be caused by infection and cardiovascular events in a fourth study [9]. As such, the control of heart failure for patients undergoing PD is of the utmost importance [2].

As the failure of volume control underpins this heart failure, such control is a significant outcome predictor in patients undergoing chronic PD [3]. In a previous report, the management of heart failure in those who are resistant to treatment or intolerant of the conventional therapies may include PD as an adjunctive therapy [10]. However, ultrafiltration failure usually underlies the development of heart failure in patients undergoing PD, necessitating their transfer to HD [4]. Therefore, strategies aimed at preventing or managing ultrafiltration failure may help them continue on PD [6]. Moreover, heart failure is a highly prevalent complication in long-term PD. Indeed, PD patients with a history of heart failure have a significantly lower overall cumulative probability of survival than those without [7]. Thus, the prevention of heart failure and its recurrence is significant. However, maintaining the required ultrafiltration for the success of PD is difficult compared with that of HD; therefore, the prediction and prevention of heart failure in PD patients is also challenging. Therefore, we aimed to determine the prognostic markers of heart failure in PD patients to facilitate better management of the disease in this group.

\section{Correlation between BNP and NT-proBNP and other parameters}

Cardiac biomarkers, such as BNP and NT-proBNP, are commonly used to diagnose CHF [11]. Pre-proBNP is 
Table 3 Logistic regression analysis for the heart failure risk using the New York Heart Association (NYHA) classification

\begin{tabular}{|c|c|c|c|c|}
\hline \multirow[t]{2}{*}{ Variables } & \multicolumn{2}{|l|}{ Univariate analysis } & \multicolumn{2}{|l|}{ Multivariate analysis } \\
\hline & Odds ratio $(95 \% \mathrm{Cl})$ & $p$ value & Odds ratio $(95 \% \mathrm{Cl})$ & $p$ value \\
\hline $\mathrm{BNP}(\mathrm{pg} / \mathrm{mL})$ & $1.001245(0.997814-1.004173)$ & 0.4415 & & \\
\hline NT-proBNP (pg/mL) & $1.000004(0.999937-1.000045)$ & 0.878 & & \\
\hline CTR (\%) & $1.318767(1.117946-1.630652)$ & 0.0005 & $0.993997(0.729318-1.323292)$ & 0.96686 \\
\hline$\Delta \mathrm{Wt}(\mathrm{kg})$ & $1.282818(0.883557-1.87272)$ & 0.1775 & & \\
\hline BUN (mg/dL) & $1.003413(0.945632-1.061421)$ & 0.9066 & & \\
\hline $\mathrm{Cr}(\mathrm{mg} / \mathrm{dL})$ & 1.191152 (0.958659-1.50156) & 0.1133 & & \\
\hline $\mathrm{TP}(\mathrm{g} / \mathrm{dL})$ & $0.453033(0.118968-1.50955)$ & 0.1987 & & \\
\hline Alb (g/dL) & $0.931232(0.272288-3.354781)$ & 0.9095 & & \\
\hline $\mathrm{Na}(\mathrm{mEq} / \mathrm{L})$ & $1.189272(0.937624-1.559409)$ & 0.1588 & & \\
\hline $\mathrm{K}(\mathrm{mEq} / \mathrm{L})$ & $0.871445(0.223551-2.944876)$ & 0.8298 & & \\
\hline $\mathrm{Cl}(\mathrm{mEq} / \mathrm{L})$ & $1.077313(0.891606-1.306353)$ & 0.4344 & & \\
\hline $\mathrm{Ca}(\mathrm{mg} / \mathrm{dL})$ & $1.389613(0.511722-3.800265)$ & 0.5123 & & \\
\hline$P(m g / d L)$ & $0.97083(0.544137-1.557301)$ & 0.91 & & \\
\hline iPTH (pg/mL) & $0.999149(0.993927-1.002533)$ & 0.676 & & \\
\hline $\mathrm{Hb}(\mathrm{g} / \mathrm{dL})$ & $0.164525(0.039334-0.433469)$ & $<0.0001$ & $0.033815(8.663 e-5$ to 4.167667$)$ & 0.17465 \\
\hline $\mathrm{Ht}(\%)$ & $0.582857(0.386609-0.784583)$ & $<0.0001$ & $1.64811(0.404336-7.504343)$ & 0.48428 \\
\hline$\beta 2 \mathrm{MG}(\mu \mathrm{g} / \mathrm{mL})$ & 1.045413 (0.982767-1.10676) & 0.146 & & \\
\hline Ferritin (ng/mL) & $1.000626(0.999164-1.001749)$ & 0.3215 & & \\
\hline T-SAT (\%) & $1.003885(0.946869-1.057841)$ & 0.8891 & & \\
\hline UV (mL/day) & 0.99893 (0.996686-1.000999) & 0.3172 & & \\
\hline Weekly Kt/N urea & $0.279798(0.030394-1.670325)$ & 0.1737 & & \\
\hline Weekly CCr $\left(\mathrm{L} /\right.$ week $\left./ 1.73 \mathrm{~m}^{2}\right)$ & 0.943727 (0.87937-0.99103) & 0.0123 & $0.94682(0.871393-1.000801)$ & 0.05492 \\
\hline DM & 3.75 (0.5997035-72.626898) & 0.1735 & & \\
\hline
\end{tabular}

synthesized in cardiac myocytes in response to ventricular wall stress and stretch, associated with greater cardiac filling pressure [12]. After the removal of a signal peptide in the cytosol, proBNP is released as either NT-proBNP or BNP from myocytes into the circulation [11, 13]. NTproBNP is the inactive form, while BNP is the active one. NT-proBNP is also more stable than BNP, having a longer half-life [13]. Previous studies have demonstrated the correlations between increases in the plasma concentrations of BNP or NT-proBNP and reductions in the estimated glomerular filtration rate (eGFR) or advances in chronic kidney disease (CKD) stage, which at least in part is likely to be because the principal route of clearance of NTproBNP is renal [11]. Furthermore, the observed correlation with eGFR was more marked for NT-proBNP than for BNP, and the ratio of NT-proBNP/BNP increased with advancing CKD stage [11]. A high NT-proBNP concentration has been shown to predict morbidity and mortality, and its concentration in patients undergoing CAPD is lower than those undergoing HD [12]. Additionally, NTproBNP is a significant predictor of cardiovascular congestion, mortality, and adverse cardiovascular outcomes in PD patients [13].
The present analysis has shown that the BNP concentration was positively correlated with that of NTproBNP. In addition, the CTR was positively correlated with BNP and NT-proBNP concentrations, but $\Delta \mathrm{Wt}$ was not correlated with these parameters. The variations in diet, clothing, or constipation may have influenced the measured $\Delta \mathrm{Wt}$, such that the reliability of the measurement may have been low.

\section{Associations with the NYHA classification}

The NYHA classification was statistically associated with both BNP and NT-proBNP. However, the associations with $\mathrm{CTR}, \mathrm{Hb}$, and $\mathrm{Ht}$ showed a higher level of significance. Also, the logistic regression model of the heart failure risk showed that $\mathrm{CTR}, \mathrm{Hb}$, and $\mathrm{Ht}$ were significantly associated with the NYHA classification in the univariate analysis, but BNP and NT-proBNP were not. However, none remained significantly associated in the multivariate analysis. These results may have been influenced by the values for BNP and NT-proBNP in NYHA category II patients being very high; therefore, a study of a larger number of patients may alter this finding. 


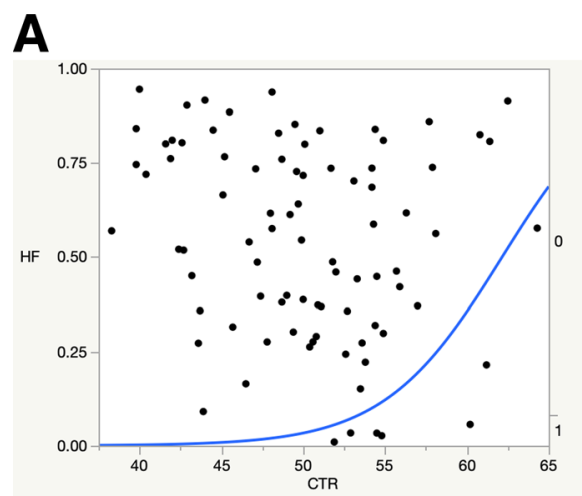

B
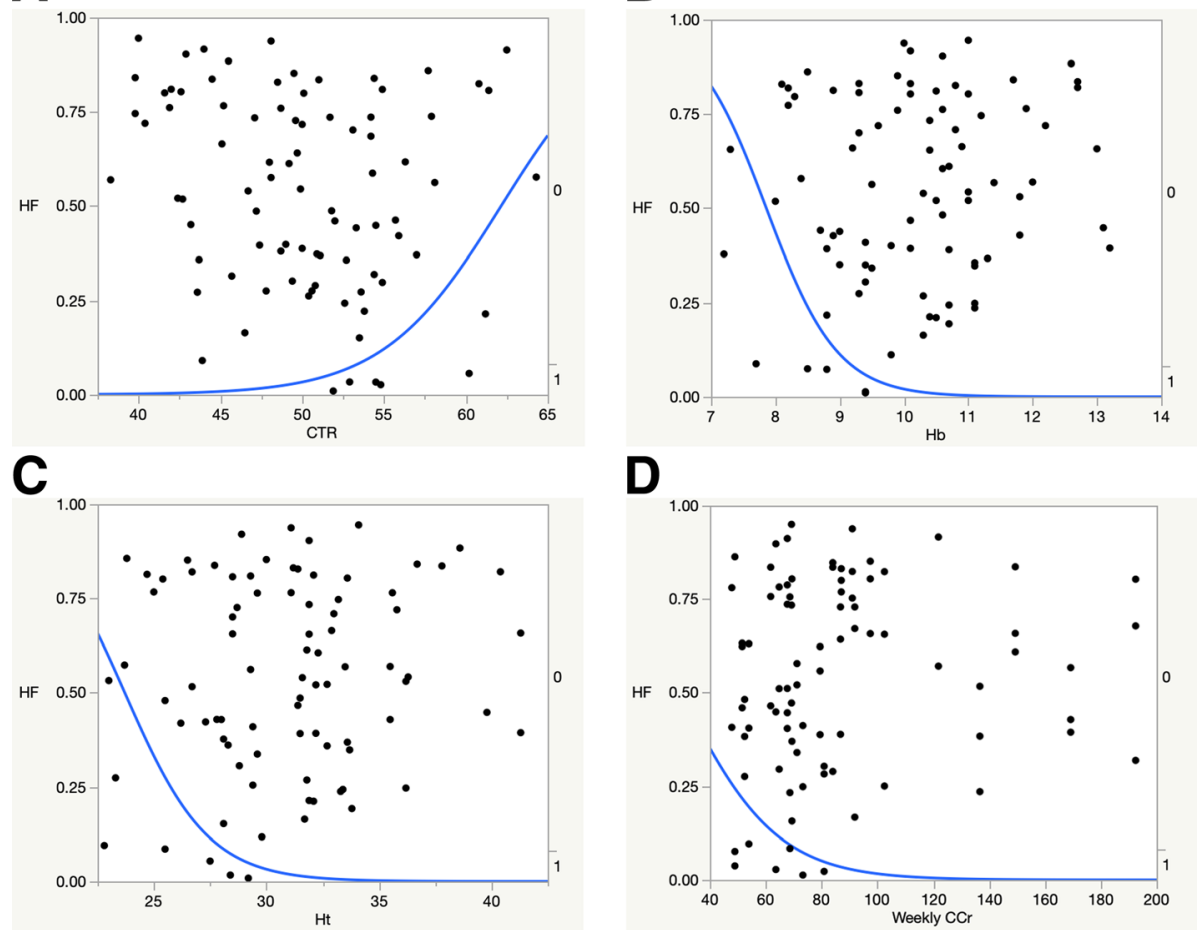

D

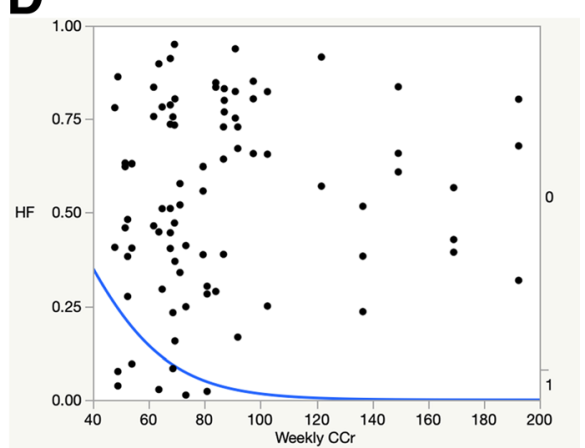

Fig. 3 Youden indexes (cutoff values) obtained from the receiver operating characteristic (ROC) curve for the New York Heart Association (NYHA) classification. CTR (a), Hb (b), Ht (c) and weekly CCr (d)

Furthermore, the relationships with weekly Kt/V urea and $\mathrm{CCr}$ were significant, but not with UV. A combined urinary and peritoneal $\mathrm{Kt} / \mathrm{V}$ urea $>1.7$ /week or $\mathrm{CCr}>$ $50 \mathrm{~L} /$ week $/ 1.73 \mathrm{~m}^{2}$ is recommended by the Renal Association Clinical Practice Guideline on PD adults and children [14]. They are associated with mortality in PD patients. Furthermore, a report has shown that the improvement of peritoneal $\mathrm{Kt} / \mathrm{V}$ urea and $\mathrm{CCr}$ reduced the rate of CHF [15]. The reason why UV was not significant may be that weekly Kt/V urea and $\mathrm{CCr}$ were calculated by not only the value of urine but also the value of PD.

\section{Logistic regression analysis of the heart failure risk using the NYHA classification}

The multivariate logistic regression analysis of the heart failure risk using the NYHA classification found that $\mathrm{CTR}, \mathrm{Hb}, \mathrm{Ht}$, and weekly $\mathrm{CCr}$ were not associated with heart failure classification. The Youden indexes (cutoff value) on the ROC curves for the NYHA classification for CTR, $\mathrm{Hb}, \mathrm{Ht}$, and weekly $\mathrm{CCr}$ were $>51.9 \%$, < $9.4 \mathrm{~g} /$ $\mathrm{dL},<29.2 \%$, and $<80.9 \mathrm{~L} /$ week $/ 1.73 \mathrm{~m}^{2}$, indicating a high risk of heart failure. Moreover, a CTR of 0.43-0.49 has been previously reported to be associated with higher inhospital mortality and poor long-term clinical outcomes [16]. However, a CTR $>0.5$ is traditionally considered abnormal, and the target $\mathrm{Hb}$ for $\mathrm{PD}$ patients has been set at $11-13 \mathrm{~g} / \mathrm{dL}$ in Japan [17]. Furthermore, as described earlier, a weekly CCr $>50 \mathrm{~L} /$ week $/ 1.73 \mathrm{~m}^{2}$ is recommended [14]. The present findings are consistent with the use of these values.

Anemia is an independent risk factor for mortality in patients with heart failure [18-20]. It is also an essential component of the cardiorenal anemia syndrome, and the severity score of this syndrome is an independent and significant predictor of death in patients undergoing PD [21]. In the present study, the logistic regression model of the heart failure risk using the NYHA classification found that CTR, $\mathrm{Hb}$, and $\mathrm{Ht}$ were significantly associated in the univariate analysis. The CTR was correlated with the anemia status of PD patients and was a reliable predictor of mortality and hospitalization-free survival $[22,23]$. In addition, it was correlated with the BNP and NT-proBNP concentrations; however, as a predictor of heart failure, it may have been significant because of this relationship with anemia. In one previous report, a lower, but not higher, $\mathrm{Hb}$ concentration was associated with higher mortality in ESA-treated PD patients [24]. Therefore, anemia in PD patients may be the more significant pathology.

Numerous studies have shown that iron deficiency is highly prevalent in patients with CHF and associated with higher risks of hospitalization and mortality [25]. 
As ferritin is an acute-phase reactant, it is often considered to be a less reliable marker than T-SAT [20]. However, with regard to their relationships with the NYHA classification, ferritin was significantly associated, while T-SAT was not, and neither was significantly associated in univariate analysis. Nevertheless, because ferritin was significant in the ANOVA, a relationship between iron metabolism and heart failure may be possible. However, this may be related to the inflammatory response that occurs in this disease because T-SAT was not associated with this and ferritin is considered to be an inflammatory substance [20]. Moreover, ferritin may have not shown a relationship in the univariate analysis because the cutoff value for NYHA grade III is too high.

A previous study has shown that intravenous (IV) iron therapy may be effective for iron deficiency anemia (IDA), but its benefit is partially independent of $\mathrm{Hb}$ concentration [20]. Other studies have demonstrated direct links between IDA and both quality of life and mortality, and iron repletion reduces the severity of the "restless legs" symptom and improves cognition, physical performance, exercise tolerance, and immune function, implying that both anemia and iron deficiency contribute to the cardiovascular risk and mortality [26].

Patients on HD have also been shown to have a superior $\mathrm{Hb}$ response when they are treated with IV iron, but this has less effect on patients with CKD [27]. Oral iron is poorly absorbed in most patients with CAPD [28]. Moreover, although it is often used in PD because of difficulties with venous access, in iron-deficient and iron-replete PD patients alike, IV iron supplementation results in larger iron stores and higher $\mathrm{Hb}$ concentrations, with fewer associated side effects than with oral iron [29]. The data on a higher risk of peritonitis or other infections in PD patients being administered IV iron have not yet been described, but one report has shown that an IV infusion of iron causes oxidative stress and inflammation in the peritoneal mesothelial cells, which may impair the viability of the peritoneum [30]. As a result, opinions vary regarding the optimal iron supplementation pathway for use in PD patients. In the present study, iron was administered orally, which is often done to PD patients because this method is simpler. However, phosphorus adsorbents containing iron, hypoxia-induced transcription factor stabilizers, orally active inhibitors of prolyl hydroxylase enzyme, and other newer and potentially more physiologic therapies are currently being studied for the treatment of anemia [24]. Furthermore, iron deficiency itself may contribute to heart failure, rather than anemia, but further studies are needed to determine this.

Kidney failure is a significant prognostic factor in patients with heart failure, and the $\mathrm{CCr}$ rate is an independent predictor of mortality [31]. The weekly $\mathrm{CCr}$ in patients undergoing PD reflects the residual renal function. Therefore, in this study, it is suggested that weekly $\mathrm{CCr}$ was statistically significant by univariate analysis and was not significant, but the highest risk of heart failure by multivariate analysis in logistic regression models were constructed for the risk of heart failure using the NYHA classification. On the other hand, the reason why weekly Kt/V was not significant in the univariate analysis may be because it reflects the clearance of only small molecules, contrary to weekly CCr. Furthermore, weekly $\mathrm{CCr}$ may reflect an effect in preventing heart failure than weekly $\mathrm{Kt} / \mathrm{V}$.

This study has certain limitations. First, it was conducted at a single center; therefore, the number of participants and duration of the study were limited. Second, the number of patients with heart failure was much lower than those without. Last, the NYHA classification used as a marker of heart failure is a subjective index. Thus, these limitations may have introduced various biases.

In conclusion, BNP and NT-proBNP, the classical markers of heart failure, were not useful in predicting this disease in PD patients. Also, the reliability of $\Delta \mathrm{Wt}$ as a marker was low. On the contrary, the weekly $\mathrm{CCr}$ was associated with the highest risk of heart failure, followed by anemia. The following were also associated with a high risk of this disease: CTR $>51.9 \%, \mathrm{Hb}<9.4 \mathrm{~g} /$ $\mathrm{dL}, \mathrm{Ht}<29.2 \%$, and weekly $\mathrm{CCr}<80.9 \mathrm{~L} /$ week $/ 1.73 \mathrm{~m}^{2}$. However, using only these indicators to predict or prevent heart failure is impossible. Therefore, further largescale trials are necessary to establish more useful markers of heart failure in PD patients.

\section{Abbreviations \\ 95\% Cl: 95\% confidence interval; Alb: Albumin; ANOVA: Analysis of variance; BMI: Body mass index; BNP: Brain natriuretic peptide; BUN: Blood urea nitrogen; CAPD: Continuous ambulatory peritoneal dialysis; $\mathrm{CCr}$ : Creatinine clearance; CHF: Congestive heart failure; Cl: Cardiac index; \\ CTR: Cardiothoracic ratio; DM: Diabetes mellitus; EF: Ejection fraction; HD: Hemodialysis; Ht: Hematocrit; iPTH: Intact parathyroid hormone; LAD: Left atrial dimension; LVMI: Left ventricular mass index; NT-proBNP: N- terminal pro-brain natriuretic peptide; NYHA: The New York Heart Association; P: Serum phosphate; PD: Peritoneal dialysis; sß2MG: Serum beta2 microgloblin; TP: Total protein; T-SAT: Ferritin and transferrin saturation; UV: Urine volume; $\Delta \mathrm{Wt}$ : Change in body weight}

\section{Acknowledgements \\ The authors thank all the participants and the staffs of NMS Hospital Blood Purification Center.}

\section{Authors' contributions}

KT performed the study and wrote the paper. YSa designed and performed the study, analyzed the data, and wrote the paper. YSu, KM, SK, FI, and TY performed the study and acquired the laboratory data with KT. ST supervised the study. All authors read and approved the final manuscript.

\section{Funding}

The authors have received no research funds.

Availability of data and materials

Please contact the authors for data requests.

Ethics approval and consent to participate

All patients provided informed consent to participate in the study after the study protocol. The present study was retrospectively registered at the 
University Hospital Medical Information Network (UMIN no. 000041762). This study was designed in accordance with the Declaration of Helsinki.

\section{Consent for publication}

Not applicable

\section{Competing interests}

The authors declare that they have no competing interests.

Received: 6 May 2019 Accepted: 21 August 2019

Published online: 02 September 2019

\section{References}

1. Patient Registration Committee, Japanese Society for Dialysis Therapy, Tokyo, JapanShigeru Nakai, Takahiro Shinzato, Tsutomu Sanaka, KenjiroKikuchi, Tateki Kitaoka, Toshio Shinoda, Chikao Yamazaki, RumiSakai, Hiroyuki Omori, Osamu Morita, Kunitoshi Iseki, KazuoKubo, Kaoru Tabei, Ikuto Masakane, Kiyohide Fushimi, AtsushiWada, Naoko Miwa, Takashi Akiba. The current state of chronic dialysis treatment in Japan (as of December 31, 2000). Therapeutic apheresis and dialysis : official peer-reviewed journal of the International Society for Apheresis, the Japanese Society for Apheresis, the Japanese Society for Dialysis Therapy 2003;7(1):3-35.

2. Saran R, Robinson B, Abbott KC, Agodoa LYC, Bhave N, Bragg-Gresham J, Balkrishnan R, Dietrich X, Eckard A, Eggers PW, Gaipov A, Gillen D, Gipson D, Hailpern SM, Hall YN, Han Y, He K, Herman W, Heung M, Hirth RA, Hutton D, Jacobsen SJ, Jin Y, Kalantar-Zadeh K, Kapke A, Kovesdy CP, Lavallee D, Leslie J, McCullough K, Modi Z, Molnar MZ, Montez-Rath M, Moradi H, Morgenstern H, Mukhopadhyay P, Nallamothu B, Nguyen DV, Norris KC, O'Hare AM, Obi Y, Park C, Pearson J, Pisoni R, Potukuchi PK, Rao P, Repeck K, Rhee CM, Schrager J, Schaubel DE, Selewski DT, Shaw SF, Shi JM, Shieu M, Sim JJ, Soohoo M, Steffick D, Streja E, Sumida K, Tamura MK, Tilea A, Tong L, Wang D, Wang M, Woodside KJ, Xin X, Yin M, You AS, Zhou H, Shahinian V. US renal data system 2017 annual data report: epidemiology of kidney disease in the United States. Am J Kidney Dis. 2018;71(3 s1):A7.

3. Wang AY, Brimble KS, Brunier G, Holt SG, Jha V, Johnson DW, Kang SW, Kooman JP, Lambie M, McIntyre C, Mehrotra R, Pecoits-Filho R: ISPD cardiovascular and metabolic guidelines in adult peritoneal dialysis patients part ii - management of various cardiovascular complications. Perit Dial Int 2015, 35(4):388-396.

4. Teitelbaum I. Ultrafiltration failure in peritoneal dialysis: a pathophysiologic approach. Blood purif. 2015;39(1-3):70-3.

5. Kawaguchi $Y$, Hasegawa T, Nakayama M, Kubo H, Shigematu T. Issues affecting the longevity of the continuous peritoneal dialysis therapy. Kidney int Suppl. 1997;62:S105-7.

6. Chaudhary K. Peritoneal dialysis drop-out: causes and prevention strategies. Int J Nephrol. 2011:2011:434608.

7. Wang AY, Wang M, Lam CW, Chan IH, Lui SF, Sanderson JE. Heart failure in long-term peritoneal dialysis patients: a 4-year prospective analysis. Clin J Am Soc Nephrol. 2011;6(4):805-12.

8. Zhang Q, Ren H, Xie J, Li X, Huang X, Chen N. Causes of death in peritoneal dialysis patients with different kidney diseases and comorbidities: a retrospective clinical analysis in a Chinese center. Int Urol Nephrol. 2014; 46(6):1201-7.

9. Sakaci T, Ahbap E, Koc Y, Basturk T, Ucar ZA, Sinangil A, Sevinc M, Kara E, Akgol C, Kayalar AO, Caglayan FB, Sahutoglu T, Unsal A. Clinical outcomes and mortality in elderly peritoneal dialysis patients. Clinics (Sao Paulo, Brazil). 2015:70(5):363-8

10. Puttagunta $\mathrm{H}$, Holt SG. Peritoneal dialysis for heart failure. Perit dial int. 2015;35(6):645-9.

11. Colbert G, Jain N, de Lemos JA, Hedayati SS. Utility of traditional circulating and imaging-based cardiac biomarkers in patients with predialysis CKD. Clin J Am Soc Nephrol. 2015:10(3):515-29.

12. Ludka O, Spinar J, Tomandl J, Konecny T. Comparison of NT-proBNP levels in hemodialysis versus peritoneal dialysis patients. Biomed Pap Med Fac Univ Palacky Olomouc Czech Repub. 2013;157(4):325-30.

13. Wang AY, Lam CW, Yu CM, Wang M, Chan IH, Zhang Y, Lui SF, Sanderson JE. N-terminal pro-brain natriuretic peptide: an independent risk predictor of cardiovascular congestion, mortality, and adverse cardiovascular outcomes in chronic peritoneal dialysis patients. J Am Soc Nephrol. 2007;18(1):321-30.
14. Woodrow G, Fan SL, Reid C, Denning J, Pyrah AN. Renal Association Clinical Practice Guideline on peritoneal dialysis in adults and children. BMC nephrol. 2017;18(1):333.

15. Paniagua R, Amato D, Vonesh E, Correa-Rotter R, Ramos A, Moran J, Mujais $S$. Effects of increased peritoneal clearances on mortality rates in peritoneal dialysis: ADEMEX, a prospective, randomized, controlled trial. J Am Soc Nephrol. 2002;13(5):1307-20.

16. Jun SJ, Jeong HC, Ku YH, Ahn S, Park KH, Sim DS, Kim JH, Jeong MH, Cho JG, Park JC, Hong YJ, Ahn Y. An optimal cardiothoracic ratio cut-off to predict clinical outcomes in patients with acute myocardial infarction. Int J Cardiovasc Imaging. 2013;29(8):1889-97.

17. Tsubakihara Y, Nishi S, Akiba T, Hirakata H, Iseki K, Kubota M, Kuriyama S, Komatsu Y, Suzuki M, Nakai S, Hattori M, Babazono T, Hiramatsu M, Yamamoto H, Bessho M, Akizawa T. 2008 Japanese Society for Dialysis Therapy: guidelines for renal anemia in chronic kidney disease. Ther Apher Dial. 2010;14(3):240-75.

18. Obi Y, Kim T, Kovesdy CP, Amin AN, Kalantar-Zadeh K. Current and potential therapeutic strategies for hemodynamic cardiorenal syndrome. Cardiorenal Med. 2016;6(2):83-98.

19. Groenveld HF, Januzzi JL, Damman K, van Wijngaarden J, Hillege HL, van Veldhuisen DJ, van der Meer P. Anemia and mortality in heart failure patients a systematic review and meta-analysis. J Am Coll Cardiol. 2008;52(10):818-27.

20. Grote Beverborg N, van Veldhuisen DJ, van der Meer P. Anemia in heart failure: still relevant? JACC Heart failure. 2018;6(3):201-8.

21. Malyszko J, Zbroch E, Malyszko J, Mysliwiec M, laina A. The cardio-renalanaemia syndrome predicts survival in peritoneally dialyzed patients. Arch Med Sci. 2010;6(4):539-44.

22. Chen KH, Hung CC, Lin-Tan DT, Huang WH, Hsu CW, Weng SM, Lin JL Cardiothoracic ratio association with mortality in patients on maintenance peritoneal dialysis. Ther Apher Dial. 2011;15(1):81-8.

23. Gao N, Kwan BC, Chow KM, Chung KY, Leung CB, Li PK, Szeto CC. Longitudinal changes of cardiothoracic ratio and vascular pedicle width as predictors of volume status during one year in Chinese peritoneal dialysis patients. Kidney Blood Press Res. 2009;32(1):45-50.

24. Molnar MZ, Mehrotra R, Duong U, Kovesdy CP, Kalantar-Zadeh K. Association of hemoglobin and survival in peritoneal dialysis patients. Clin J Am Soc Nephrol. 2011;6(8):1973-81.

25. Kang CK, Pope M, Lang CC, Kalra PR. Iron deficiency in heart failure: efficacy and safety of intravenous iron therapy. Cardiovasc Ther. 2017;35(6).

26. Zeidan A, Bhandari S. Anemia in peritoneal dialysis patients; iron repletion, current and future therapies. Perit Dial Int. 2017;37(1):6-13.

27. Rozen-Zvi B, Gafter-Gvili A, Paul M, Leibovici L, Shpilberg O, Gafter U. Intravenous versus oral iron supplementation for the treatment of anemia in CKD: systematic review and meta-analysis. Am J Kidney Dis. 2008;52(5):897-906.

28. Domoto DT, Martin KJ. Failure of CAPD patients to respond to an oral iron absorption test. Adv Perit Dial. 1992:8:102-4

29. Johnson DW. Intravenous versus oral iron supplementation in peritoneal dialysis patients. Perit Dial Int. 2007;27(Suppl 2):S255-60.

30. Breborowicz A, Polubinska A, Kupczyk M, Wanic-Kossowka M, Oreopoulos DG. Intravenous iron sucrose changes the intraperitoneal homeostasis. Blood Purif. 2009;28(1):53-8.

31. Zamora E, Lupon J, Urrutia A, Gonzalez B, Mas D, Diez C, Altimir S, Valle V. Prognostic significance of creatinine clearance rate in patients with heart failure and normal serum creatinine. Rev Esp Cardiol. 2007;60(12):1315-8.

\section{Publisher's Note}

Springer Nature remains neutral with regard to jurisdictional claims in published maps and institutional affiliations. 